\title{
Metolachlor e Fomesafen Aplicados Via Irrigação por Aspersão em Plantio Direto e Convencional ${ }^{1}$
}

\author{
Metolachlor and Fomesafen Applied Via Sprinkler Irrigation under Conventional and No-Till \\ Systems
}

FONTES, J.R.A. ${ }^{2}$, SILVA, A.A. ${ }^{3}$, VIEIRA, R.F. ${ }^{4}$ e RAMOS, M.M. ${ }^{5}$

\begin{abstract}
RESUMO - Objetivou-se com este trabalho avaliar a eficácia do metolachlor e do fomesafen aplicados com água de irrigação (herbigação) no controle de plantas daninhas na cultura do feijão, em plantio direto e convencional. O plantio direto foi implantado sobre palha de milho e de plantas daninhas. No plantio convencional, o preparo de solo foi feito com uma aração e duas gradagens. A variedade de feijão utilizada foi a Pérola, semeada no final de julho. O metolachlor e o fomesafen foram aplicados em pré-emergência e pós-emergência, respectivamente, utilizando um pivô central. O metolachlor $\left(2,4 \mathrm{~kg} \mathrm{ha}^{-1}\right)$ foi aplicado com lâminas de água de 5, 10 e $15 \mathrm{~mm}$, e o fomesafen $\left(0,225 \mathrm{~kg} \mathrm{ha}^{-1}\right)$, com 3,6 e $9 \mathrm{~mm}$. Os herbicidas também foram aplicados por pulverização. Foram incluídas duas testemunhas: feijão com e sem capina. Quatro dias antes e quatro dias depois da aplicação do metolachlor foi aplicada lâmina de água de $10 \mathrm{~mm}$ em toda a área experimental. A espécie daninha predominante no plantio direto foi Bidens pilosa e, no plantio convencional, Artemisia verlotorum. Outras espécies de plantas daninhas que ocorreram na área experimental foram agrupadas em outras dicotiledôneas e monocotiledôneas. O nível de controle de plantas daninhas foi, em geral, melhor com a herbigação que com a pulverização, independentemente do sistema de plantio. As lâminas de água de 5 ou $10 \mathrm{~mm}$, para o metolachlor, e de 3 ou $6 \mathrm{~mm}$, para o fomesafen, proporcionaram, em geral, os melhores resultados. As produtividades alcançadas no plantio direto foram maiores, em relação ao plantio convencional.
\end{abstract}

Palavras-chave: herbigação, herbicidas, controle, sistemas de plantio.

\begin{abstract}
ABSTRAC - The aim of this study was to evaluate the efficacy of metolachlor (2.4 $\mathrm{kg}$ a.i. $\mathrm{ha}^{-1}$ ) and fomesafen $\left(0.225 \mathrm{~kg}\right.$ a.i. ha $\left.\mathrm{a}^{-1}\right)$ applied via a center pivot on weed control in the common bean plant (Phaseolus vulgaris). The cultivar Pérola was sown in July (winter). Metolachlor was applied with water volume of 5, 10, and $15 \mathrm{~mm}$, and fomesafen with 3, 6, and $9 \mathrm{~mm}$. The herbicides were also sprayed. Two checks were included: with and without weeds. The predominant weed in the no-till system was Bidens pilosa and in the conventional tillage, Artemisia verlotorum. In general, herbigation was more efficient than spray for weed control, regardless of the type of tillage system. Water volume of 5 or $10 \mathrm{~mm}$ for metolachlor, and 3 or $6 \mathrm{~mm}$ for fomesafen, yielded the best results, overall.
\end{abstract}

Keywords: herbigation, herbicides, weed control, tillage systems.

1 Recebido para publicação em 18.4.2005 e na forma revisada em 24.2.2006.

2 Eng.-Agr., Dr., Pesquisador, Embrapa Amazônia Ocidental, Caixa Postal 319, 69048-660 Manaus-AM, <zeroberto@cpaa.embrapa.br>, ${ }^{3}$ Eng.-Agr., Dr., Professor, Departamento de Fitotecnia da Universidade Federal de Viçosa UFV, 36570-000 Viçosa-MG. ${ }^{4}$ Eng.-Agr., Dr., Pesquisador Embrapa-Epamig, Viçosa-MG. ${ }^{5}$ Eng.-Agr., Dr., Professor, Departamento de Engenharia Agrícola da UFV.

Planta Daninha, Viçosa-MG, v. 24, n. 1, p. 99-106, 2006 


\section{INTRODUÇÃO}

O controle químico de plantas daninhas na cultura do feijão apresenta como vantagens a alta eficácia e seletividade dos herbicidas, a rapidez da operação e o baixo custo. O metolachlor e o fomesafen são herbicidas registrados para essa cultura. O metolachlor controla espécies monocotiledôneas e dicotiledôneas, e o fomesafen, dicotiledôneas (Rodrigues \& Almeida, 2005).

O método de aplicação mais utilizado é a pulverização. Entretanto, a aplicação de herbicidas via água de irrigação, ou herbigação, tem sido adotada por muitos agricultores. Essa modalidade oferece como vantagens a distribuição uniforme dos herbicidas, o aproveitamento econômico do equipamento de irrigação, a redução da compactação do solo e a melhor incorporação e ativação dos herbicidas usados em pré-plantio incorporado ou em préemergência (Barnes et al., 1992; Vieira \& Silva, 1998). Com freqüência, no plantio direto, a eficácia de herbicidas aplicados em préemergência é reduzida com o aumento da quantidade de palha na superfície do solo, pois ela pode reter parte do produto aplicado, impedindo-o de atingir o alvo. Ou seja, a adsorção desses herbicidas aos restos culturais pode reduzir-lhes a bioatividade ou mesmo impedir que atinjam o solo. Banks \& Robinson (1986) verificaram que a palhada de trigo reduziu a eficácia dos herbicidas acetochlor, alachlor e metolachlor aplicados por pulverização. Segundo Helling et al. (1988) e Mills et al. (1989), os restos culturais sobre a superfície do solo interceptam herbicidas, deixando-os mais expostos a raios solares, altas temperaturas e ventos, acelerando-lhes a fotodecomposição e a volatilização. Nesse aspecto, Ferri \& Vidal (2002) constataram menor persistência do acetochlor em solo cultivado no sistema plantio direto, quando comparada àquela verificada no plantio convencional.

Estudos demonstraram que o metolachlor aplicado via herbigação apresentou eficácia no controle de plantas daninhas semelhante à obtida com a sua aplicação por pulverização (Barnes et al., 1992). Quando aplicado com a água de irrigação, sua incorporação no perfil do solo é rápida, o que diminui as perdas por fotodecomposição e/ou volatilização. Ademais, segundo Vieira \& Silva (1998), em solos mais úmidos, o metolachlor fica mais disponível em solução, facilitando-lhe a absorção pela plântula, e, conseqüentemente, há melhor eficácia de controle.

Experimentos conduzidos por Dowler (1984, 1987) mostraram que a mistura do fomesafen com óleo de soja ou óleo mineral não-emulsificante, feita antes da herbigação, proporcionou excelente controle de Ipomoea purpurea, Jacquemontia tamnifolia, Desmodium tortuosum, Senna obtusifolia, Richardia scabra e Amaranthus sp. Vieira \& Fontes (1994) verificaram excelente controle de $B$. pilosa, mas não de espécies do gênero Ipomoea, com a aplicação do fomesafen misturado com óleo de soja na proporção 1:1. Leite et al. (1999) avaliaram a eficácia do fomesafen aplicado em mistura com óleo de soja, também na proporção $1: 1$, ou água, com lâminas de água de 3, 6 e 9 mm, constatando ausência de intoxicação aos feijoeiros, independentemente da mistura utilizada, e que o aumento da lâmina de água melhorou o controle de $R$. raphanistrum. É importante ressaltar que não ocorreu chuva nem foi realizada irrigação na cultura durante a condução do experimento. Segundo esses autores, parece que a absorção radical do fomesafen contribuiu para aumentar o nível de controle. Fontes et al. (1999) obtiveram controle de 95\% de Raphanus raphanistrum com a aplicação do fomesafen com lâmina de água de $3 \mathrm{~mm}$, sem adição de óleo vegetal.

Objetivou-se com este trabalho avaliar a eficácia dos herbicidas metolachlor e fomesafen aplicados em pré e pós-emergência dos feijoeiros, respectivamente, com três lâminas de água, em sistemas de plantio direto e convencional.

\section{MATERIAL E MÉTODOS}

O trabalho foi conduzido na Fazenda Experimental da Universidade Federal de Viçosa, Viçosa-MG, em um Argissolo VermelhoAmarelo Câmbico, sob pivô central, cuja área foi dividida em duas partes iguais: metade cultivada no sistema plantio direto e metade em plantio convencional.

O metolachlor $\left(2,4 \mathrm{~kg} \mathrm{ha}^{-1}\right)$ foi aplicado em pré-emergência com lâminas de água de

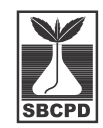


5,10 e $15 \mathrm{~mm}$ aplicadas por pivô central; e o fomesafen $\left(0,225 \mathrm{~kg} \mathrm{ha}^{-1}\right)$, em pós-emergência, na mesma área, com 3, 6 e $9 \mathrm{~mm}$. Os herbicidas também foram aplicados por pulverização, utilizando um pulverizador pressurizado a dióxido de carbono, equipado com barra de dois metros, portando bicos do tipo leque (TT 110.02), espaçados de $0,5 \mathrm{~m}$ e com pressão de $3 \mathrm{kgf} \mathrm{cm}^{-2}$, calibrado para aplicar 200 litros de calda por hectare. Além disso, foram utilizadas duas testemunhas: uma com capina (realizada com enxada) e uma sem capina.

Para aplicação das lâminas de água, a área experimental foi dividida em 12 setores com forma de cunha, cada um com ângulo de $30^{\circ}$. As lâminas foram dispostas alternadamente em seis dos 12 setores, de modo que entre dois setores úteis posicionava-se o pivô central, para iniciar e/ou finalizar a aplicação de determinada lâmina. As parcelas (repetições) foram locadas aos 15, 50 e $80 \mathrm{~m}$ em relação ao centro do pivô, em cada setor útil. As testemunhas e as parcelas pulverizadas, por independerem das lâminas de água aplicadas, tiveram apenas uma parcela locada em cada um dos setores úteis.

A área do plantio direto foi formada sobre palhada de milho e vegetação daninha, dessecadas com a aplicação de glyphosate e 2,4-D (1,08 e $0,72 \mathrm{~kg} \mathrm{ha}^{-1}$, respectivamente). Por ocasião da semeadura verificou-se que a superfície do solo estava irregularmente coberta pela palhada, deixando à mostra a sua superfície em alguns locais. No plantio convencional, o preparo de solo foi realizado por meio de aração e duas gradagens, um dia antes do plantio.

A semeadura da variedade de feijão Pérola foi feita 15 dias após a aplicação dos herbicidas dessecantes, ou seja, em 28/7/1999. O espaçamento entre fileiras foi de $0,45 \mathrm{~m}$, com distribuição de 15 sementes por metro de sulco. A adubação de plantio constou de $600 \mathrm{~kg} \mathrm{ha}^{-1}$ da formulação 4-14-8 $\left(\mathrm{N}-\mathrm{P}_{2} \mathrm{O}_{5}-\right.$ $\mathrm{K}_{2} \mathrm{O}$ ).

Para aplicação dos herbicidas, dos outros defensivos e da uréia, utilizou-se um pivô central de média pressão.

Para injeção da solução herbicida na água de irrigação utilizou-se uma bomba hidráulica de diafragma.
A herbigação do metolachlor foi feita um dia após a semeadura do feijão, e a do fomesafen, aos 25 dias após a emergência das plântulas, quando as plantas daninhas apresentavam um ou dois pares de folhas (dicotiledôneas) ou dois perfilhos (monocotiledôneas). As pulverizações foram realizadas nos mesmos dias das herbigações, entre 6h e 6 h30 da manhã. As capinas (testemunha) foram realizadas aos 14 e 28 dias após a emergência das plântulas.

Durante as herbigações, foram colocadas sobre as parcelas - que, posteriormente, receberam os herbicidas pelo método convencional - armações metálicas revestidas com filme de polietileno transparente. Essas armações, com $3,0 \mathrm{~m}$ de comprimento e $1,8 \mathrm{~m}$ de largura, foram retiradas logo após a aplicação dos herbicidas via água. Portanto, a parcela experimental foi constituída por quatro fileiras de $3,0 \mathrm{~m}$ de comprimento e $1,8 \mathrm{~m}$ de largura. A área útil foi formada por duas fileiras centrais, descontando-se 0,5 m em cada extremidade.

Os coeficientes de uniformidade de distribuição de água do sistema foram determinados segundo a metodologia da ABNT (1985). Na herbigação com o metolachlor, os coeficientes de uniformidade de Christiansen (CUC) foram de 91,5 e $91,9 \%$ no plantio direto e no convencional, respectivamente. Na herbigação do fomesafen, eles foram de 87,1 e 90,1\%, no sistema plantio direto e no convencional, respectivamente. De acordo com Mantovani \& Ramos (1994), esses valores são ótimos para pivô central, indicando boa uniformidade de distribuição de água. Além disso, segundo Threadgill (1985), esses valores são adequados para aplicação de defensivos químicos via pivô central.

A adubação em cobertura com $100 \mathrm{~kg} \mathrm{ha}^{-1}$ de uréia foi feita 32 dias após a semeadura, por fertirrigação. O controle de pragas foi realizado com deltamethrine $\left(3,75 \mathrm{~g} \mathrm{ha}^{-1}\right)$ via água de irrigação (insetigação), em 18/9/1999, com lâmina de água média de $6 \mathrm{~mm}$. Para prevenção de doenças, aplicou-se o fungicida epoxiconazole $\left(12,5 \mathrm{~g} \mathrm{ha}^{-1}\right)$ via água de irrigação (fungigação), com lâmina de água média de 5 mm, em 20/9, 4/10 e 18/10/1999.

$\mathrm{Na}$ avaliação da eficácia de controle de plantas daninhas foram adotados dois procedimentos, ambos implementados por ocasião

Planta Daninha, Viçosa-MG, v. 24, n. 1, p. 99-106, 2006 
da colheita do feijão. O primeiro constou da avaliação visual, sendo atribuídos graus de controle com base na orientação da Sociedade Brasileira da Ciência das Plantas Daninhas (SBCPD, 1995), como descrito na Tabela 1. O segundo consistiu da coleta de plantas daninhas, por espécie, das parcelas experimentais. Essas plantas foram cortadas rente ao solo, num total de duas amostragens, ao acaso, por parcela. Para isso, foi utilizado quadrado de ferro de 0,3 $\mathrm{m}$ de lado $\left(0,09 \mathrm{~m}^{2}\right)$. Após a coleta, as plantas foram acondicionadas em sacos de papel e levadas a laboratório, para serem separadas por espécie, contadas e colocadas em estufa com circulação forçada de ar a $72{ }^{\circ} \mathrm{C}$, até atingirem peso constante, para determinação da massa.

Tabela 1 - Níveis de controle de plantas daninhas utilizados para avaliação do experimento. Coimbra-MG, 1999

\begin{tabular}{|c|l|}
\hline $\begin{array}{c}\text { Porcentagem de } \\
\text { controle }\end{array}$ & \multicolumn{1}{|c|}{ Descrição do controle } \\
\hline (A) $90-100$ & Excelente ou total \\
\hline (B) $80-89$ & Bom, aceitável para infestação da área \\
\hline (C) $70-79$ & Moderado, insuficiente para infestação da área \\
\hline (D) $50-69$ & Deficiente ou inexpressivo \\
\hline (E) $0-50$ & Ausência de controle \\
\hline
\end{tabular}

Fonte: SBCPD (1995).

A colheita foi realizada em 25/11/1999. Durante essa operação foi feita a avaliação do estande final. Após a secagem dos grãos até atingirem $13 \%$ de água, foi estimada a produtividade de grãos por hectare.

$\mathrm{Na}$ interpretação dos resultados utilizouse a estatística descritiva, com apresentação das médias de tratamentos e respectivos errospadrão. No caso da herbigação, as médias foram calculadas com base nos resultados das três repetições dentro de cada lâmina de água, para cada sistema de plantio. Em se tratando das pulverizações e das testemunhas, utilizaram-se, nos cálculos, os dados obtidos nas três parcelas distribuídas em cada sistema de plantio (uma parcela em cada setor).

\section{RESULTADOS E DISCUSSÃO}

Verificou-se, na área de plantio direto, a predominância de Bidens pilosa, e na de plantio convencional, a de Artemisia verlotorum.
Além dessas espécies, as que ocorreram em menor freqüência foram agrupadas em: a) outras dicotiledôneas (Ageratum conyzoides, Ipomoea grandifolia, Ipomoea purpurea, Lepidium virginicum, Emilia sonchifolia, Oxalis corniculata, Euphorbia heterophylla, Galinsoga parviflora e Phyllanthus tenellus) e b) monocotiledôneas (Brachiaria plantaginea, Digitaria horizontalis, Eleusine indica, Cynodon dactylon e Cyperus rotundus).

As herbigações do metolachlor seguida do fomesafen promoveram excelente controle de A. verlotorum em ambos os sistemas de plantio e com todas as lâminas de água (Tabela 2). O controle da planta daninha com as pulverizações foi moderado (plantio convencional) ou não houve (plantio direto). Neste último caso, parte dos herbicidas pode ter ficado retida na camada de palha, o que reduziu a quantidade do ingrediente ativo que atingiu o solo e favoreceu as perdas por volatilização e/ou fotodecomposição. Segundo Banks \& Robinson (1986), Helling et al. (1988), Mills et al. (1989) e Ferri \& Vidal (2002), os restos culturais sobre a superfície do solo interceptam herbicidas, tornando-os mais expostos a raios solares, altas temperaturas e ventos.

No plantio convencional, a pulverização dos herbicidas proporcionou melhor controle que no plantio direto, ainda que moderado. De acordo com Barnes et al. (1992) e Vieira \& Silva (1998), a herbigação pode ser mais eficaz do que a pulverização porque proporciona melhor incorporação do herbicida aplicado em pré-emergência no solo, menos perda por volatilização e/ou fotodecomposição e, conseqüentemente, melhor atividade sobre a planta daninha.

A aplicação dos herbicidas, com todas as lâminas de água, proporcionou controle excelente de B. pilosa, em ambos os sistemas de plantio (Tabela 3). Esse bom controle deve ser creditado mais ao fomesafen que ao metolachlor, pois, de acordo com Lorenzi (1994), aquele herbicida é eficiente no controle dessa espécie (85 a 95\%), situação diferente do metolachlor (menor que 50\%). Segundo Vieira et al. (2003), para que o herbicida aplicado em pós-emergência seja eficaz na herbigação, ele precisa ter uma ou mais destas características: baixa solubilidade em água, rápida absorção pela folhagem e absorção pelas 
raízes. O fomesafen possui as duas últimas características.

No plantio direto, todos os tratamentos proporcionaram excelente controle das dicotiledôneas. No plantio convencional, as aplicações com as duas menores lâminas controlaram $100 \%$ das plantas daninhas, enquanto a pulverização e as aplicações com as maiores lâminas (15 mm para o metolachlor e $9 \mathrm{~mm}$ para o fomesafen) controlaram 83\% delas (Tabela 4). Não se encontrou explicação para esse fato.

A aplicação dos herbicidas por ambos os métodos proporcionou excelente controle das espécies monocotiledôneas tanto na área de plantio direto quanto na de plantio convencional (Tabela 5).

Independentemente do método de aplicação e do sistema de plantio, a associação dos herbicidas metolachlor e fomesafen promoveu excelente controle total das plantas daninhas (Tabela 6).

A aplicação do metolachlor, em pré-emergência, e do fomesafen, em pós-emergência, por qualquer método de aplicação e nos dois sistemas de plantio, não afetou o estande final (Tabela 7). As produtividades não foram influenciadas pelos métodos de aplicação dos herbicidas. Houve, porém, efeito dos sistemas de plantio sobre a produtividade. Em média, a produtividade do feijoeiro alcançada no sistema de plantio direto foi $23 \%$ superior à obtida no plantio convencional, provavelmente em razão da menor variação térmica e da maior reserva de água e de nutrientes do solo na área de plantio direto (dados não apresentados).

O não-controle das plantas daninhas reduziu a produtividade do feijoeiro em 78 e $75 \%$, no sistema plantio direto e no convencional, respectivamente.

Tabela 2 - Eficácia avaliada na colheita do feijão, de aplicações do metolachlor $\left(2,4 \mathrm{~kg} \mathrm{ha}^{-1}\right)$ seguida do fomesafen $\left(0,225 \mathrm{~kg} \mathrm{ha}^{-1}\right)$ via herbigação e por pulverização no controle de Artemisia verlotorum, em plantio direto (PD) e convencional (PC). Coimbra-MG, 1999

\begin{tabular}{|c|c|c|c|c|c|}
\hline \multirow{2}{*}{\multicolumn{2}{|c|}{ Tratamento avaliado }} & \multicolumn{2}{|c|}{ Massa seca $\left(\mathrm{g} \mathrm{m}^{-2}\right)$} & \multicolumn{2}{|c|}{ Controle (\%) } \\
\hline & & \multirow{2}{*}{$\frac{\mathrm{PD}}{1,2 \mathrm{r} 0,6}$} & \multirow{2}{*}{$\frac{\mathrm{PC}}{7,9 \text { r 2,45 }}$} & \multirow{2}{*}{$\frac{\mathrm{PD}}{91 \mathrm{~A}}$} & \multirow{2}{*}{$\frac{\mathrm{PC}}{91 \mathrm{~A}}$} \\
\hline \multirow{3}{*}{ Herbigaçãa $^{\underline{1} /}$} & 5 e $3 \mathrm{~mm}$ & & & & \\
\hline & 10 e $6 \mathrm{~mm}$ & 1,4 r 0,08 & 6,3 r 1,05 & $90 \mathrm{~A}$ & $94 \mathrm{~A}$ \\
\hline & 15 e $9 \mathrm{~mm}$ & 1,5 r 0,7 & 1,4 r 0,03 & $88 \mathrm{~B}$ & $98 \mathrm{~A}$ \\
\hline \multicolumn{2}{|c|}{ Pulverização $\left(200 \mathrm{~L} \mathrm{ha}^{-1}\right)$} & 11,4 r 2,33 & 21,0 r 1,55 & $11 \mathrm{E}$ & $75 \mathrm{C}$ \\
\hline \multicolumn{2}{|c|}{ Testemunha Com Capina } & $1,1 \mathrm{r} 0,12$ & 5,9 r 1,1 & $92 \mathrm{~A}$ & $93 \mathrm{~A}$ \\
\hline \multicolumn{2}{|c|}{ Testemunha Sem Capina } & 12,8 r 0,7 & 82,9 r 3,5 & - & " - \\
\hline
\end{tabular}

As letras nas colunas significam: A - controle excelente; B - controle bom; C - controle moderado; D - controle deficiente; E - ausência de controle. 1/ 5,10 e $15 \mathrm{~mm}$ para o metolachlor e 3,6 e $9 \mathrm{~mm}$ para o fomesafen.

Tabela 3 - Eficácia avaliada na colheita do feijão, de aplicações do metolachlor $\left(2,4 \mathrm{~kg} \mathrm{ha}^{-1}\right)$ seguida do fomesafen $\left(0,225 \mathrm{~kg} \mathrm{ha}{ }^{-1}\right)$ via herbigação e por pulverização no controle de Bidens pilosa, em plantio direto (PD) e convencional (PC). CoimbraMG, 1999

\begin{tabular}{|c|c|c|c|c|c|}
\hline \multirow{2}{*}{\multicolumn{2}{|c|}{ Tratamento avaliado }} & \multicolumn{2}{|c|}{ Massa seca $\left(\mathrm{g} \mathrm{m}^{-2}\right)$} & \multicolumn{2}{|c|}{ Controle $(\%)$} \\
\hline & & \multirow{2}{*}{$\frac{\mathrm{PD}}{4,8 \mathrm{r} 0,48}$} & \multirow{2}{*}{$\frac{\mathrm{PC}}{0,2 \mathrm{r} 0,06}$} & \multirow{2}{*}{$\frac{P D}{95 \mathrm{~A}}$} & \multirow{2}{*}{$\begin{array}{l}\mathrm{PC} \\
94 \mathrm{~A}\end{array}$} \\
\hline \multirow{3}{*}{ Herbigação $^{\underline{1}}$} & 5 e $3 \mathrm{~mm}$ & & & & \\
\hline & 10 e $6 \mathrm{~mm}$ & $3,7 \mathrm{r} 1,3$ & 0,0 & $96 \mathrm{~A}$ & $100 \mathrm{~A}$ \\
\hline & $15 \mathrm{e} 9 \mathrm{~mm}$ & $0,1 \mathrm{r} 0,04$ & 0,0 & $97 \mathrm{~A}$ & $100 \mathrm{~A}$ \\
\hline \multicolumn{2}{|c|}{ Pulverização $\left(200 \mathrm{~L} \mathrm{ha}^{-1}\right)$} & 0,0 & 0,0 & $99 \mathrm{~A}$ & $100 \mathrm{~A}$ \\
\hline \multicolumn{2}{|c|}{ Testemunha Com Capina } & 0,0 & 0,3 r 0,01 & $100 \mathrm{~A}$ & $91 \mathrm{~A}$ \\
\hline \multicolumn{2}{|c|}{ Testemunha Sem Capina } & 101,9 r 13,03 & 3,4 r 0,23 & - & - \\
\hline
\end{tabular}

As letras nas colunas significam: A - controle excelente.

1/ 5,10 e $15 \mathrm{~mm}$ para o metolachlor e 3,6 e $9 \mathrm{~mm}$ para o fomesafen. 
Tabela 4 - Eficácia avaliada na colheita do feijão, de aplicações do metolachlor $\left(2,4 \mathrm{~kg} \mathrm{ha}^{-1}\right)$ seguida do fomesafen $\left(0,225 \mathrm{~kg} \mathrm{ha}^{-1}\right)$ via herbigação e por pulverização no controle de outras dicotiledôneas ${ }^{1 /}$, em plantio direto (PD) e convencional (PC). Coimbra-MG, 1999

\begin{tabular}{|c|c|c|c|c|c|}
\hline \multirow{2}{*}{\multicolumn{2}{|c|}{ Tratamento avaliado }} & \multicolumn{2}{|c|}{ Massa seca $\left(\mathrm{g} \mathrm{m}^{-2}\right)$} & \multicolumn{2}{|c|}{ Controle $(\%)$} \\
\hline & & PD & $\mathrm{PC}$ & PD & PC \\
\hline \multirow{3}{*}{ Herbigação ${ }^{1 /}$} & 5 e $3 \mathrm{~mm}$ & 0,0 & 0,0 & $100 \mathrm{~A}$ & $100 \mathrm{~A}$ \\
\hline & 10 e $6 \mathrm{~mm}$ & 0,0 & 3,0 r 0,95 & $100 \mathrm{~A}$ & $97 \mathrm{~A}$ \\
\hline & 15 e $9 \mathrm{~mm}$ & $0,3 \times 0,03$ & 6,9 r 1,26 & $95 \mathrm{~A}$ & $93 \mathrm{~A}$ \\
\hline \multicolumn{2}{|c|}{ Pulverização $\left(200 \mathrm{~L} \mathrm{ha}^{-1}\right)$} & 0,0 & 0,3 r 0,09 & $100 \mathrm{~A}$ & $95 \mathrm{~A}$ \\
\hline \multicolumn{2}{|c|}{ Testemunha Com Capina } & 1,4 r 0,01 & 0,6 r 0,02 & $90 \mathrm{~A}$ & $90 \mathrm{~A}$ \\
\hline \multicolumn{2}{|c|}{ Testemunha Sem Capina } & 17,5 r 1,85 & 5,9 r 2,4 & - & - \\
\hline
\end{tabular}

As letras nas colunas significam: A - controle excelente; B - controle bom.

1/ Ageratum conyzoides, Ipomoea grandifolia, Ipomoea purpurea, Lepidium virginicum, Emilia sonchifolia, Oxalis corniculata, Euphorbia heterophylla, Galinsoga parviflora e Phyllanthus tenellus. 뇌 5,10 e $15 \mathrm{~mm}$ para o metolachlor e 3, 6 e 9 mm para o fomesafen.

Tabela 5 - Eficácia avaliada na colheita do feijão, de aplicações do metolachlor $\left(2,4 \mathrm{~kg} \mathrm{ha}^{-1}\right)$ seguida do fomesafen $\left(0,225 \mathrm{~kg} \mathrm{ha}^{-1}\right)$ via herbigação e por pulverização no controle de monocotiledôneas ${ }^{\prime \prime}$, em plantio direto (PD) e convencional (PC). Coimbra-MG, 1999

\begin{tabular}{|c|c|c|c|c|c|}
\hline \multirow{2}{*}{\multicolumn{2}{|c|}{ Tratamento avaliado }} & \multicolumn{2}{|c|}{ Massa seca $\left(\mathrm{g} \mathrm{m}^{-2}\right)$} & \multicolumn{2}{|c|}{ Controle $(\%)$} \\
\hline & & \multirow{2}{*}{$\frac{P D}{0,0}$} & \multirow{2}{*}{$\frac{\mathrm{PC}}{0,0}$} & \multirow{2}{*}{$\frac{\mathrm{PD}}{100 \mathrm{~A}}$} & \multirow{2}{*}{$\frac{\mathrm{PC}}{100 \mathrm{~A}}$} \\
\hline \multirow{3}{*}{ 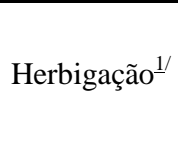 } & 5 e $3 \mathrm{~mm}$ & & & & \\
\hline & 10 e $6 \mathrm{~mm}$ & 0,0 & $3,0 \mathrm{r} 0,95$ & $100 \mathrm{~A}$ & $97 \mathrm{~A}$ \\
\hline & 15 e $9 \mathrm{~mm}$ & 0,3 r 0,03 & 6,9 r 1,26 & $95 \mathrm{~A}$ & $93 \mathrm{~A}$ \\
\hline \multicolumn{2}{|c|}{ Pulverização $\left(200 \mathrm{~L} \mathrm{ha}^{-1}\right)$} & 0,3 r 0,09 & 2,3 r 0,85 & $95 \mathrm{~A}$ & $98 \mathrm{~A}$ \\
\hline \multicolumn{2}{|c|}{ Testemunha Com Capina } & 0,6 r 0,02 & $2,9 r 1,65$ & $90 \mathrm{~A}$ & $97 \mathrm{~A}$ \\
\hline \multicolumn{2}{|c|}{ Testemunha Sem Capina } & 5,9 r 2,4 & 100,9 r 8,4 & - & - \\
\hline
\end{tabular}

As letras nas colunas, de acordo com a SBCPD (1995), significam: A - controle excelente.

1/ Brachiaria plantaginea, Digitaria horizontalis, Eleusine indica, Cynodon dactylum e Cyperus rotundus. $\stackrel{2 /}{5}, 10$ e 15 mm para o metolachlor e 3, 6 e $9 \mathrm{~mm}$ para fomesafen.

Tabela 6 - Eficácia avaliada na colheita do feijão, de aplicações do metolachlor $\left(2,4 \mathrm{~kg} \mathrm{ha}^{-1}\right)$ seguida do fomesafen $\left(0,225 \mathrm{~kg} \mathrm{ha}^{-1}\right)$ via herbigação e por pulverização no controle do total de plantas daninhas, em plantio direto (PD) e convencional (PC), Coimbra-MG, 1999

\begin{tabular}{|c|c|c|c|c|c|}
\hline \multirow{2}{*}{\multicolumn{2}{|c|}{ Tratamento avaliado }} & \multicolumn{2}{|c|}{ Massa seca $\left(\mathrm{g} \mathrm{m}^{-2}\right)$} & \multicolumn{2}{|c|}{ Controle $(\%)$} \\
\hline & & \multirow{2}{*}{$\frac{\text { PD }}{7,0 \text { r } 0,99}$} & \multirow{2}{*}{$\frac{\mathrm{PC}}{8,1 \mathrm{r} 2,22}$} & \multirow{2}{*}{$\frac{\mathrm{PD}}{99 \mathrm{~A}}$} & \multirow{2}{*}{$\frac{\mathrm{PC}}{96 \mathrm{~A}}$} \\
\hline \multirow{3}{*}{ Herbigação $^{\underline{1} /}$} & 5 e $3 \mathrm{~mm}$ & & & & \\
\hline & 10 e $6 \mathrm{~mm}$ & 6,3 r 1,06 & $20,3 \times 2,01$ & $95 \mathrm{~A}$ & $90 \mathrm{~A}$ \\
\hline & 15 e $9 \mathrm{~mm}$ & 4,6 r 2,34 & 8,6 r 1,55 & $97 \mathrm{~A}$ & $95 \mathrm{~A}$ \\
\hline \multicolumn{2}{|c|}{ Pulverização $\left(200 \mathrm{~L} \mathrm{ha}^{-1}\right)$} & $11,7 \times 1,85$ & 20,6 r 3,3 & $92 \mathrm{~A}$ & $90 \mathrm{~A}$ \\
\hline \multicolumn{2}{|c|}{ Testemunha Com Capina } & $3,1 \mathrm{r} 0,06$ & 9,2 r 2,05 & $98 \mathrm{~A}$ & $95 \mathrm{~A}$ \\
\hline \multicolumn{2}{|c|}{ Testemunha Sem Capina } & 138,1 r 13,12 & 189,0 r 23,68 & - & - - \\
\hline
\end{tabular}

As letras nas colunas significam: A - controle excelente.

1/ 5,10 e $15 \mathrm{~mm}$ para o metolachlor e 3,6 e $9 \mathrm{~mm}$ para o fomesafen. 
Tabela 7 - Efeitos das aplicações do metolachlor $\left(2,4 \mathrm{~kg} \mathrm{ha}^{-1}\right)$ seguida do fomesafen $\left(0,225 \mathrm{~kg} \mathrm{ha}^{-1}\right)$ via herbigação e por pulverização sobre o estande final e a produtividade do feijoeiro cultivado em plantio direto (PD) e convencional (PC). Coimbra-MG, 1999

\begin{tabular}{|c|c|c|c|c|c|}
\hline \multirow{2}{*}{\multicolumn{2}{|c|}{ Tratamento avaliado }} & \multicolumn{2}{|c|}{ Estande final (plantas $\mathrm{m}^{-2}$ ) } & \multicolumn{2}{|c|}{ Produtividade $\left(\mathrm{kg} \mathrm{ha}^{-1}\right)$} \\
\hline & & \multirow{2}{*}{$\frac{\mathrm{PD}}{23,4 \text { r 2,1 }}$} & \multirow{2}{*}{$\frac{\mathrm{PC}}{22,1 \text { r } 1,7}$} & \multirow{2}{*}{$\frac{\mathrm{PD}}{2.728 \mathrm{r} 118}$} & \multirow{2}{*}{$\frac{\mathrm{PC}}{1.946 \mathrm{r} 87}$} \\
\hline \multirow{3}{*}{ Herbigação ${ }^{1 /}$} & 5 e $3 \mathrm{~mm}$ & & & & \\
\hline & 10 e 6 mm & 23,1 r 0,5 & 22,4 r 1,1 & 2.668 r 65 & 1.837 r 371 \\
\hline & 15 e 9 mm & 22,9 r 0,9 & 22,7 r 0,1 & $2.506 r 56$ & 2.041 r 66 \\
\hline \multicolumn{2}{|c|}{ Pulverização $\left(200 \mathrm{~L} \mathrm{ha}^{-1}\right)$} & $23,3 \times 2,2$ & 23,7 r 1,8 & 2.706 r 89 & 2.327 r 32 \\
\hline \multicolumn{2}{|c|}{ Testemunha Com Capina } & 24,6 r 0,6 & 24,6 r 3,1 & 2.652 r 42 & 2.096 r 48 \\
\hline \multicolumn{2}{|c|}{ Testemunha Sem Capina } & $23,5 \times 2,2$ & 23,5 r 2,3 & 569 r 147 & 503 r 182 \\
\hline \multicolumn{2}{|c|}{ Média } & $23,5 \times 1,4$ & 23,1 r 1,6 & 2.305 r 86 & 1.792 r 31 \\
\hline
\end{tabular}

1/ 5,10 e $15 \mathrm{~mm}$ para o metolachlor e 3,6 e $9 \mathrm{~mm}$ para o fomesafen.

A aplicação dos herbicidas metolachlor e fomesafen com água de irrigação foi eficaz no controle de plantas daninhas e não causou toxicidade aos feijoeiros em plantio direto ou convencional.

\section{LITERATURA CITADA}

ASSOCIAÇÃO BRASILEIRA DE NORMAS TÉCNICAS ABNT. Sistema de irrigação por aspersão pivô central: caracterização de desempenho/método de ensaio. Rio de Janeiro: 1985. 22 p. (Projeto de norma, 12:02.08-005).

BANKS, P. A.; ROBINSON, E. L. Soil reception and activity of acetochlor, alachlor, and metolachlor as affected by wheat (Triticum aestivum) straw and irrigation. Weed Sci., v. 34, n. 4, p. 607-611, 1986.

BARNES, C. J.; LAVY, T. L.; TALBERT, R. E. Leaching, dissipation, and efficacy of metolachlor applied by chemigation or conventional methods. J. Environ. Qual., v. 21, n. 2, p. 232-236, 1992.

DOWLER, C. C. Present herbicide application technology with sprinkler irrigation. Soil Crop Science Society of Florida, n. 3, p. 6-9, 1984.

DOWLER, C. C. Efficacy of some recently developed herbicides applied through irrigation. In: SOUTHERN WEED SCIENCE SOCIETY, 40., 1987, Orlando. Proceedings... Champaign: SWSS, 1987. p. 372.

FERRI, M. V. W.; VIDAL, R. A. Persistência do acetochlor em solo sob semeadura direta e convencional. Planta Daninha, v. 20, n. 1, p. 133-139, 2002.

FONTES, J. R. A. et al. Aplicação de herbicidas em pósemergência via água de irrigação na cultura do feijão. In: REUNIÃO NACIONAL DE PESQUISA DE FEIJÃO, 6., Salvador, 1999. Anais... Santo Antônio de Goiás: Embrapa CNPAF, 1999. v. 1. p. 459-461.
HELLING, C. S. et al. Persistence and leaching of atrazine, alachlor, and cyanazine under no-tillage practices.

Chemosphere, v. 17, n. 1, p. 175-187, 1988.

LEITE, J. A. O. et al. Aplicação do herbicida fomesafen, com e sem óleo, em três lâminas de água na cultura do feijão. In: REUNIÃO NACIONAL DE PESQUISA DE FEIJÃO, 6. Salvador, 1999. Anais... Santo Antônio de Goiás: Embrapa CNPAF, 1999. v. 1. p. 462-464.

LORENZI, H. Manual de identificação e controle de plantas daninhas - plantio direto e convencional. 5.ed. Nova Odessa: Plantarum, 2000. 383 p.

MANTOVANI, E. C.; RAMOS, M. M. Manejo da irrigação. In: COSTA, E. F.; VIEIRA, R. F.; VIANA, P. A.

Quimigação - aplicação de produtos químicos e biológicos via irrigação. Brasília: Embrapa/SPI, 1994. p. 129-158.

MILLS, J. A.; WITT, W. W. Effect of tillage systems on the efficacy and phytotoxicity of imazaquin and imazethapyr in soybean (Glycine max). Weed Sci., v. 37, n. 2, p. 233-238, 1989.

RODRIGUES, B. N.; ALMEIDA, F. R. Guia de herbicidas. 5.ed. Londrina: Edição dos autores, 2005. 591 p.

SOCIEDADE BRASILEIRA DA CIÊNCIA DAS PLANTAS DANINHAS - SBCPD. Procedimentos para instalação, avaliação e análise de experimentos com herbicidas. Londrina: 1995. $42 \mathrm{p}$.

THREADGILL, E. D. Current status and future of chemigation. In: NATIONAL SYMPOSIUM ON CHEMIGATION, 3., 1985, Tifton. Proceedings... Tifton: Rural Development Center, 1985. p. 1-12.

VIEIRA, R. F.; FONTES, J. R. A. Aplicação da mistura dos herbicidas fomesafen e fluazifop-p-butil por intermédio da água de irrigação de pivô central, na cultura do feijão (Phaseolus vulgaris L.). In: CONGRESSO BRASILEIRO DE INICIAÇÃO CIENTÍFICA EM CIÊNCIAS AGRÁRIAS, 14., 1994, Viçosa-MG. Resumos... Viçosa-MG: Universidade Federal de Viçosa, 1994. p. 176.

Planta Daninha, Viçosa-MG, v. 24, n. 1, p. 99-106, 2006 
VIEIRA, R. F.; SILVA, A. A. Aplicação de defensivos via água de irrigação por aspersão. In: VIEIRA, C.; PAULA JR., T. J.; BORÉM, A. (Ed.). Feijão - aspectos gerais e cultura no Estado de Minas. Viçosa: Editora UFV, 1998. p. 13-17.
VIEIRA, R. F.; SILVA, A. A.; RAMOS, M. M. Aplicação de herbicidas pós-emergentes via irrigação por aspersão - revisão. Planta Daninha, v. 21, n. 3, p. 495-506, 2003. 